\title{
"Expressions of personhood in Alzheimer's": Moving from ethnographic text to performing ethnography
}

\author{
Kontos, P., Naglie, G. \\ Version Post-Print/Accepted Manuscript \\ Citation Kontos, P., Naglie, G. "Expressions of personhood in Alzheimer's": \\ (published version) Moving from ethnographic text to performing ethnography. Qualitative \\ Research 2006; 6(3):301-317. \\ Publisher's Statement This is the peer reviewed version of the article, which has been \\ published in final form at \\ http://dx.doi.org/10.1177/1468794106065005.
}

\section{How to cite TSpace items}

Always cite the published version, so the author(s) will receive recognition through services that track citation counts, e.g. Scopus. If you need to cite the page number of the TSpace version (original manuscript or accepted manuscript) because you cannot access the published version, then cite the TSpace version in addition to the published version using the permanent URI (handle) found on the record page. 
"Expressions of Personhood in Alzheimer's": Moving from Ethnographic Text to Performing Ethnography

(C) Pia C. Kontos $^{1}$ \& Gary Naglie ${ }^{2}, 2005$

${ }^{1}$ Pia C. Kontos, PhD

Postdoctoral Fellow, Toronto Rehabilitation Institute

${ }^{2}$ Gary Naglie, MD

Clinician Scientist, Toronto Rehabilitation Institute and University Health Network;

Associate Professor, Departments of Medicine, Health Policy, Management and

Evaluation, University of Toronto

Direct all correspondence to:

Dr. Pia C. Kontos

Postdoctoral Fellow

Toronto Rehabilitation Institute

550 University Ave., Suite 1124

Toronto, ON M5G 2A2

Canada

TEL: (416) 597-3422, ext. 3449

FAX: (416) 597-7105

Email: kontos.pia@ torontorehab.on.ca 


\section{"Expressions of Personhood in Alzheimer's": Moving from Ethnographic Text to \\ Performing Ethnography}

Introduction

In Western science, the written text, the most objective, decontextualized, and disengaged discursive style of communication, is the privileged mode of scholarship (Conquergood, 1991; Denzin, 1997; Paget, 1993). Not even qualitative inquiry is immune to the textualist bias of Western science, where knowledge about lived experience acquired through an intensely participatory methodology is ultimately figured visually as text (fieldnotes, transcribed interviews, and written interpretations). However, the "atemporal, decontextualized, flattening approach of text-positivism" (Conquergood, 1991: 189) has not gone without critique by researchers engaged with qualitative methodologies. Ethnographers, for example, have long recognized the irony that even though ethnographic fieldwork privileges practical, personal and participatory experience in the field, when translated into published ethnographies the interpersonal contingencies and engagement of fieldwork are smoothed into an expository prose of abstract theory and analysis (Clifford, 1988). The limits of textualism are even more pronounced in the paradigm of embodiment where the existential immediacy of the body (perceptual experience, modes of presence, and engagement in the world) becomes an objectified abstraction when subjugated to the semantic (Csordas, 1994).

Ethnographers and other qualitative scholars are challenged to find alternative strategies for knowledge generation and representation that redress the limits of textualism. Blending diverse approaches, plural knowledges, and shared expertise from rhetoric, performance and the human sciences has yielded new aesthetics that incorporate methodologies from art, theatre, literature and various other genres. Subsumed under a 
new paradigm of social inquiry, these aesthetics invoke a multisensual, multiperspectival epistemology that does not privilege the written text.

This paper discusses the alliance between ethnography and performance, an interdisciplinary configuration referred to interchangeably as ethnoperformance (Paget, 1993), ethnodrama (Mienczakowski, 2001; Mienczakowski et al., 2002), and the anthropology of performance (Turner, 1986). It is a genre within ethnography that is appealing to a new generation of scholars committed not just to describing the world but also to changing it (Denzin, 2000). As an example of this new aesthetic practice we discuss the transformation of ethnographic research on embodied selfhood in Alzheimer's disease (Kontos, 2004b) into a dramatic production for nurses and ancillary health care professionals working with persons who are cognitively impaired. The rationale for using drama to translate and disseminate these research findings is threefold: 1) to provide an accessible presentation of research to audiences of diverse disciplinary backgrounds; 2) to recover the experiential immediacy of the body present in the original data gathering setting which, in the case of this dramatic production, permits a powerful demonstration of how selfhood is manifested in gesture and action; and 3) to create a space to engage in a form of social inquiry that resonates simultaneously with critique and the envisioning of new possibilities (Denzin, 1997). Expressions of Personhood in Alzheimer's is a production that not only re-presents embodied expressions of selfhood in Alzheimer's disease, but also critically exposes depersonalizing tendencies of treatment contexts and caregiving relationships that are a consequence of an assumed loss of selfhood that is widely associated with the cognitive deficiencies that lie at the core of dementia. It is our contention that this ethnodramatic production has the potential to open a space for seeing 
the humanity of persons with dementia, and for envisioning the prospect of a truly humanistic approach to dementia care practice.

We begin with a brief discussion of the performance paradigm, including its origins and various uses and forms. Then we describe the original research upon which Expressions of Personhood in Alzheimer's is based as well as the rationale for translating the findings of this research into a dramatic performance. Finally, we detail the various stages of its development including script writing, meetings with the artistic troupe to explore the findings of the original research, as well as the methodological challenges of bringing the body-based theoretical framework explicit in the scripts to the stage.

\section{The performance paradigm}

The use of art in the conduct and dissemination of social science research has strongly been advocated by Eisner (1988; 1998), a scholar whose use of critical qualitative methods from the arts to study and improve educational practice has exercised tremendous influence in the qualitative research community. Central to Eisner's aesthetic approach to educational inquiry is his contention that methods from the arts ought to be incorporated into the expanding array of educational research methods because the arts enable us to discern meanings that would otherwise remain transparent if we worked only in the linear scientific mode. He argues that artistic expression through drama, painting, sculpture, film, music, and the dynamic forms of dance has not received sufficient attention in curriculum development endeavors or discussions of teaching methods and that there should be greater use of drama, film, literature, and the visual arts in school curriculum, and more broadly, in the presentation of research. 
Further to Eisner's influential work on arts-based research is the politicaltheatrical mandate of Boal, the Brazilian theater director, writer, and theorist, whose theatre techniques have significantly shaped the way that social and health scientists have incorporated drama into their research (Denzin, 1997; Mienczakowski, 1995). Boal developed the Theater of the Oppressed, a method of teaching people who are not actors how to recognize oppression in their lives and how to possibly transform the conditions that create their oppression. The theatrical goal is to engage those who are disempowered and to create ways to liberate the disenfranchised. Participants shape the circumstances of their oppression into scenes in which one protagonist tries to prevail against the set of oppressive constraints represented by an antagonist (Boal, 1992). A unique feature of the Theater of the Oppressed is that there is no hierarchical separation of scriptwriter, director, actors and audience. The audience members, appropriately referred to by Boal as "spect-actors", often participate in the development of the performance text, exploring with the actors and director new forms of oppression and resistance (Heritage, 1994). The dialogic relationship between stage and audience is an important form of improvisational theatre that has influenced qualitative researchers in their use of performance.

A pivotal figure in initiating the alliance between the aesthetic of performance and the methodological and theoretical ambitions of research is Turner (Conquergood, 1991, 1992; Fabian, 1990). His initial call for the use of performance in ethnographic research was prompted by his recognition that human beings are first and foremost performers (Turner, 1986). Turner's insight that performance events and processes are fundamental to culture has inspired scholars to rethink culture and identity as constructed and relational instead of ontologically given. As Conquergood points out, Turner was drawn 
to the performance paradigm because its focus on face-to-face encounters and its insistence upon the intricate and nuanced dramaturgy of everyday life allow ethnographers to retrieve "the saying from the said", and to "shift their enterprise from nouns to verbs, from mimesis to kinesis, from textualized space to co-experienced time" (Conquergood, 1991: 183).

Turner's insistence that social life is performative rather than informative was pushed even further by Fabian (1990) who conceptualizes performance as both the way individuals creatively realize their culture and give expression and meaning to experience, and as a method by which ethnographers achieve deeper understanding of that culture. Fabian himself developed a play about cultural conceptions of power in postcolonial urban Africa in collaboration with a theatrical group in Shaba, Zaire. He explains that it is through a collaborative process of brainstorming, which entailed extensive dialogue and the exchange of local sayings and customs with the theatrical group, that he and the actors achieved a richer understanding of local conceptions of power.

In addition to being used as a method for revealing and generating meaning for the researcher and the researched, performance also represents an innovative approach to disseminating the results of qualitative studies (Gray et al., 2001; Gray et al., 2000). Performance has become a qualitative vehicle for the translation and dissemination of research findings, making data more accessible and meaningful to a wider cross section of the general public (Mienczakowski et al., 2002). Gray et al. echo these sentiments in their assertion that the linking of qualitative research to dramatic productions is a new field that has enormous potential to shift "the influence of research outward from 
universities and other academic settings, to include communities that were originally studied and the general public" (2002: 69). Qualitative health researchers are increasingly using drama to make their research more vital, tangible, and relevant to health care settings, what Mienczakowski has termed "health theatre" (2002: 35) that predominantly targets "health audiences" (health consumers, carers of health consumers, health professionals, and health educators). Gray et al. (2000), for example, have used drama to extend their research findings beyond the discipline of clinical psychology. The research-based production, entitled Handle with Care? Women Living with Metastatic Breast Cancer, premised on the results of two qualitative research studies - one conducted with women with metastatic breast cancer to better understand the issues they face, and another conducted subsequently with medical oncologists treating breast cancer patients to explore with them the issues raised by the women in the first study - is exemplary of how a production of drama can successfully translate research findings and disseminate the information to multiple audiences (Gray et al., 2000; Sinding et al., 2002). No Big Deal? (Gray et al., 2003), based upon a study about the experiences of men with prostate cancer and their spouses is another example of the effectiveness of drama as a dissemination strategy. In post-performance evaluations, physicians (primarily oncologists and urologists), nurses, and allied health professionals indicated that attending the performance resulted in a new level of awareness or understanding of how patients are affected by cancer diagnosis and treatment (Gray et al., 2003). This suggests that research-based drama, in communicating research findings more directly and effectively to health professionals, can change attitudes, and, in doing so, holds the potential to change practice as well. 
Mienczakowski has similarly expressed dissatisfaction with the usual dissemination practice of publishing academic manuscripts. Motivated by the oftenneglected responsibility for researchers to have their work make a difference in the everyday world, he has developed numerous research-based productions in order to better inform service providers, health professionals and the general public of how, for example, schizophrenia (Mienczakowski, 1992) and substance abuse (Mienczakowski \& Morgan, 1993) are experienced. In collaboration with the Faculties of Nursing, Health Sciences, and Education and the Arts at Griffith University, these productions were performed by nursing, education and theatre students for selected service providers and health care professionals in residential psychiatric settings, as well as for general audiences of school and tertiary students and interested others (Mienczakowski, 1999). These performances were intended to raise awareness and understanding of these health and social issues (Mienczakowski, 1999).

Qualitative researchers have experimented with various forms of performance that Denzin, in his discussion of all such forms, has divided conceptually into two broad categories: 1) performance science model; and 2) "improvisational ethnodrama" (1997: 100). In the first category, performances are based solely on the texts of data gathered via qualitative methods of inquiry (interviews, fieldwork notes, etc.), what Stucky calls the "first order performance source of the text" (1993: 173). The goal of these performances is a mix of mimesis and verisimilitude in the re-creation of the circumstances and experiences of the original data-gathering site and its meanings. The second category of performance is consistent with "a critical, postmodern, performance aesthetic" (Denzin, 1997: 113) and takes authority away from the original text, "producing composite 
characters, emphasizing multiple tellings of the same event, and shifting concern away from verisimilitude toward dramatic reinterpretation and cultural critique" (1997: 100). Mienczakowski describes this form of performance as "public voice ethnography" (2001: 469) because of the interactionist data-gathering methodology of ethnodrama. As Mienczakowski (1999) explains, performances are constantly revised according to data generated by post-performance discussions with informants and audience members introducing a dialogic engagement in the production of the ethnodramatic script. In this way the script is never completed and is always under revision.

Denzin (1997) describes the performance paradigm as being caught between $r e$ presentational theatre, where the impulse is to valorize ordinary lived experience with high verisimilitude, and presentational theatre, which embraces full improvisation, audience co-participation, and cultural critique. In its re-creation of on-stage verisimilitude, Denzin argues that re-presentational theatre confines itself "within the spaces of a modernist aesthetic and a postpositivist (at best) epistemology" (1997: 114), and, consequently fails to critique the reality it reproduces on stage. Denzin's critical appraisal of re-presentational theatre rests on the assumption that one must enter an improvisational space in order to move an audience to critical awareness and action. While improvisational ethnodrama clearly has enormous emancipatory and educational potential (Mienczakowski, 2001), it is our contention that it is by no means the only form of performance that can lead to critical awareness and action. To assume that rerepresentational theatre cannot be critical because it fails to "open a space for the audience as coperformers to...create new understandings of the experiences being described and interpreted" (Denzin, 1997: 115), is to overlook that performances with 
high verisimilitude can foster critical awareness and engage audiences to envision new possibilities.

Contra Denzin's assertions about re-presentational theatre, we shall argue that Expressions of Personhood in Alzheimer's stands as an example of a dramatic production with high verisimilitude, but one that links critical qualitative research to drama. It is a production that shifts the discourse on selfhood in Alzheimer's disease towards greater recognition of embodiment. It does so by disentangling selfhood from the cognitive categories upon which long-standing notions of selfhood are based, and emphasizing how the body is a substantive means by which persons with advancing dementia remain engaged with the world. However, the critical impetus of the production is not only in that it challenges prevalent assumptions about the nature of personhood in Alzheimer's; it is also inherent in our use of the production to implement a larger research agenda of ours to humanize the practice of dementia care (Kontos, 2005).

\section{Ethnographic reflections on selfhood, embodiment and Alzheimer's}

Explicit in the current construction of Alzheimer's disease is the assumption that memory impairment caused by cognitive deficiencies leads to a steady loss of selfhood. As Fontana and Smith state, with the onset and progression of Alzheimer's disease, what is actually happening is that the self is becoming "increasingly devoid of content - it is 'unbecoming' a self' (1989: 36). Davis echoes these sentiments by maintaining that, "what is so devastating about the relentless nature of dementia is the very splintering of the sedimented layers of Being", until ultimately "there is nothing left" (2004: 375). In traditional approaches to caregiving, the principles of practice are largely informed by the assumption that dementia is a disease that "eradicates the essence of the person" (Dalziel, 
1994). This is most apparent when we consider the depersonalizing tendencies of some treatment contexts and caregiving relationships. Several investigators have lamented the prevalence of negative attitudes towards individuals with Alzheimer's disease in nursing homes. Norberg and Asplund (1990), for example, write that most staff in their study believed that residents with severe cognitive impairment experience life as meaningless. Ekman et al. (1991) found that caregivers spend less time with severely cognitively impaired residents and respond more negatively to them as compared to residents whose cognition is intact.

The insistence that selfhood is the exclusive privilege of the sphere of cognition has its origins in the modern Western philosophical tradition that separates mind from body, and positions the former as superior to the latter. This dichotomy suggests a fundamental passivity of the body, since it is primarily cognition that is held to be essential to selfhood. Informed by a theoretical framework of embodiment (Kontos, 2004a, 2004b), Kontos' ethnographic study of selfhood in Alzheimer's disease ${ }^{1}$ (2004b; 2005) challenges the assumed erasure of selfhood with cognitive impairment. It is argued that despite even severe cognitive impairment, selfhood persists as an embodied dimension of human existence.

With mounting empirical evidence that person-centred approaches to care facilitate the achievement of positive health outcomes and enhance quality of life (Luker et al., 2000; Whittemore, 2000), it is clear that the key task in dementia care must be the maintenance of personhood. Though the need for person-centred approaches to dementia care is widely advocated (Jonas-Simpson, 2001; Kitwood, 1997; Tappen et al., 1999), as Kontos (2005) argues, personhood itself must be understood in its full corporeal 
complexity for dementia care to truly become person-centred. As a first step towards the development of dementia care practices premised on the notion of embodied selfhood, Kontos designed a study to conduct focus groups with nurses and ancillary health care professionals to explore with them the meaning of the concept of embodied selfhood in the context of their practice, and how this new concept could enhance person-centred dementia care.

When designing the research methodology for this study, Kontos was aware that for health care professionals to reflect on the notion of embodied selfhood in the context of their practice, an understanding of this notion would be crucial. This would nonetheless be difficult to achieve through traditional ways of communicating science (textual abstract theory and analysis) because of the multidisciplinary makeup of the focus groups (nursing, occupational therapy, physiotherapy, recreational therapy) and because all disciplines involved are distinct from social science. Therefore, given the ineffectiveness of social science discourse in addressing this particular audience, an alternative method of dissemination would be required, one that goes beyond the constraints of conventional reporting approaches of academic writing, by giving the text a lifelike dimension.

Following the lead of Stucky (1993), Mienczakowski (1999; 2001; 2002), Gray et al. $(2002 ; 2000)$ and others who argue that drama guarantees an accessibility not ensured by styles of academic report writing, Kontos chose to use performance to communicate her research findings. But even more significantly, in the case of Kontos' research, drama would prove to be the most appropriate dissemination strategy given the body-based theoretical perspective to be communicated to the focus group participants. Embodied 
selfhood emphasizes a corporeal form of knowledge that exists below the level of consciousness and language, beyond the reach of introspective scrutiny, for it is enacted at a pre-reflective level (Kontos, 2004b; 2005). Embodied selfhood is a concept that draws upon Maurice Merleau-Ponty's phenomenological understanding of nonrepresentational intentionality and the primordial body (1962), and upon Pierre Bourdieu's concept of habitus, which links bodily dispositions to socio-culturally specific conditions of primary socialization $(1977 ; 1990)$. It goes beyond the scope of this paper to fully explicate Merleau-Ponty's and Bourdieu's theoretical approaches to the body (for a more lengthy discussion of these ideas see Kontos, 2004a and 2004b). What is of relevance here is that both Merleau-Ponty and Bourdieu speak of our primary relation to the world as consisting in practical competence, emphasizing a kind of awareness or practical reason that exists primarily in corporeal ways. Kontos understands selfhood as inhering in a pre-reflective level and thus as enacted in what Merleau-Ponty refers to as the body's primordial or natural power of expression and in what Bourdieu refers to as the socio-cultural specificity of the movements of the body (Kontos, 2004b; 2005). Utilizing dramatic performance as an alternative medium for communication would thus redress the limits of textualism in two important respects: First, by providing an accessible presentation of the research to the focus group participants who are of diverse disciplinary backgrounds; and second, by recovering the experiential immediacy of the body that was present in the original data-gathering situation.

In Kontos' research, the original data-gathering situation was ethnographic fieldwork on an Alzheimer's support unit where she conducted participant observation. With an interest in exploring embodiment in the face of the severe cognitive impairment 
that occurs with Alzheimer's disease, the lived world was the most proximate terrain where embodiment could be explored. It is not, however, an easy task to describe bodies in motion.

Phelan (1997), in her treatment of performance art, discusses the difficulties of moving from direct observation of physical action to textual documentation. She notes that in performance, the central object of attention, the moving body, is continually disappearing, and it is precisely the transience of the body in action that is so difficult to translate into discourse. Kontos encountered this difficulty in her efforts to document the study participants' habitual states, tendencies, and inclinations to act and speak in a particular way. For example, she describes the importance that gesture played in interpersonal communication (Kontos, 2004b), often serving the purpose of conveying praise, blame, thanks, support, affection, gratitude, disapproval, dislike, sympathy, greeting, and so forth. Slight head nods, eye and small lip movements, chin thrusts, shoulder nods, hand and finger movements, as well as leg and foot shifts were communicative and interactive. A short sequence of acts might signal for another resident's attention: a directed gaze towards another person, a smile, a lift of an eyebrow, a wave and a quick head nod. Likewise, gaze avoidance signaled a desire not to communicate, often accompanied by particular body movements or postures, such as turning away. Intonation changes and the rise or fall of pitch level were also difficult to document. As Kontos describes (2004b), the Yiddish language has an expressiveness that manifests itself in the rhythm of speech. There is a great deal of emotion in the highs and lows of the voices of her study participants. As the sounds go up and down in melody one can feel the words as much as hear them. 
The active, participatory nature of fieldwork privileges communicating bodies, thus enabling the researcher to attend to such finely detailed speech and nuanced gesture. It is only by attending to the body in the lived world of everyday life that Kontos, for example, achieved the insight that the socio-cultural specificity of selfhood is visibly manifested in the way that the body moves, perceives, and behaves. However, as noted by Clifford (1986; 1988), Conquergood (1991), and others, the dynamic, intimate, precarious and embodied experiences observed in the field become one-dimensional in their textual representation. Denzin (1997) draws upon Bakhtin's (1986) analysis of dialogical communication to articulate his critique of the privileging of text in the ethnographic project. According to Denzin, for Bakhtin the interactional situation is thoroughly contextual and immediate. It is a context whose meaning rests on shared knowledge and taken-for-granted assumptions of the speaker and listener. The unsaid, the assumed, and the silences and pauses mediate and connect the speaker's meanings with their talk. This "double voicedness of talk" (Denzin, 1997: 38), the way a word or utterance is inflected and given bodily and facial expression is critical for understanding, and yet lost or muted in academic discourse. Denzin thus concludes that textual representations "crumble precisely at that moment when... [they] are taken to be a measure of pure presence, pure interaction...” (1997: 36). The visual image is never a pure copy of lived experience because textualism mutes the physical, emotional, visceral, and sensory dimensions of communication, flattening out "the flux of human relationships, the ways meanings are created intersubjectively as well as intertextually, embodied in gestures as well as in words..." (Jackson quoted in Conquergood, 1991: 188). The challenge is for ethnography to "evoke" experience rather than to "represent" 
experience (Tyler, 1987), a difficult challenge to meet with textual representation being the privileged epistemological modality.

In contrast, dramatic performance privileges the phenomenological complexity of everyday life and thus, just as with participant observation, it too has the advantage of drawing the observer into a particular social and cultural world. As Denzin argues (1997), the performed text recovers the experiences previously represented in the ethnographer's text and then re-presents those experiences as embodied performance. By "doubling back" on the original ethnographic experiences of being directly involved in people's daily lives, observing and talking with them, learning how they respond to situations, how they organize their lives, etc., what is recovered is precisely what gets lost in the translation of participant observation into textual documentation - the textures, sounds, gestures, and movements of the lived world.

Kontos' rationale for translating her ethnographic research findings into drama is that performance would provide the focus group participants with a more direct pathway to how selfhood is manifested in gesture and action, and is centered in complex face-toface interactions, than could be achieved through conventional dissemination practices (e.g. academic discourse). Performance would thus enrich and intensify the focus group participants' understanding of embodied selfhood. As Saldaña asserts "the best lens for fieldwork views human action "dramatistically"” (2003: 231). Performance would also provide the focus group participants with the opportunity to observe a re-presentation of health care staff in their daily care giving practice. Dramatically portraying interactions between staff and individuals with Alzheimer's disease would facilitate the focus group participants' recognition of missed opportunities for health care staff to respond to and 
support the selfhood of persons with cognitive impairment in its embodied manifestations, but also to appreciate moments of genuine deep caring. Thus, translating Kontos' ethnographic data into drama would facilitate and enrich the discussion amongst the focus group participants about embodied selfhood and ways in which this concept may broaden the scope and opportunities for the development of interpersonal relationships between health care staff and care recipients.

\section{Bringing the text to life: Moving from text to performance}

In the development of the dramatic performance, Kontos felt it necessary to remain faithful to realistic, "in life" scenes, such as were actually described in her fieldnote text, precisely because of what was descriptively captured in the text. Emerging from the description of her research findings is a narrative about social etiquette, friendship, humour, conflict, gestural communication, and religious observance. It is therefore a narrative about human relationships, both amicable and quarrelsome, and the commonplace elements of day-to-day social interaction. This might initially seem to be rather mundane and unexceptional, however, when the context of the narrative is considered, an Alzheimer's support unit, the significance of the narrative is far from mundane. Despite even severe cognitive impairment of the study participants, their gestural communication and basic bodily movements were replete with coherence, and even spontaneity, and thus powerfully challenge the prevailing assumption that individuals with Alzheimer's disease or other dementias lose what is presumed to define our humanness: selfhood. Thus, for the performance, Kontos sought to recover from the field observations and to re-enact the habitual states, tendencies, and inclinations of the study participants that render visible their selfhood, precisely because they so powerfully 
disturb commonplace assumptions and would thus offer insight and stimulate discussion amongst the focus group participants.

In Kontos' doctoral dissertation, a number of observed occurrences from her fieldnotes were written as vignettes in order to present these occurrences more extensively, not because they were isolated cases, but rather because of their prominence as examples of expressions of embodied selfhood. Five of these vignettes were chosen for the development of the scripts. The following is an example of one such vignette:

\section{String of Pearls}

Molly's wheelchair looked enormous next to her thin and shriveled body. Her legs had severely atrophied leaving a seemingly two-dimensional form. Were she able to stand, she'd be no more than five feet tall. Her face was heavily wrinkled but her skin soft, resembling a peach. Her hair was uniformly white which accentuated her China-blue eyes. The back of her hands was the most vivid testament to the near century she had lived. The skin was thin revealing a network of bones and purple veins. Her hands shook as if powered by an invisible gentle motor.

Despite her withered appearance there was an indescribable elegance to her. I noticed this in watching Molly as she was brought to the dining room. Once her wheelchair was positioned at the table a bib was fastened around her neck. Molly then carefully unfolded her napkin and placed it on her lap. Even though the use of the bib made the need for a napkin redundant, she nonetheless insisted in observing this table etiquette.

As a Health Care Aide was feeding her, cereal dribbled from Molly's mouth and coursed down her chin. When the Health Care Aide tried to give her another spoonful Molly wrinkled her forehead and gently pushed the woman's hand away. Molly then lifted her bib to her mouth to wipe the cereal. It was only after her chin was clean that she accepted another spoonful. One might expect indifference from a woman who has lost the ability to feed herself and yet Molly's insistence to adhere to a sense of social grace and her attention to neatness, suggested a strong and continuing presence.

She closed her eyes slowly and opened them again releasing a deep sigh. She then looked around the table as if for the first time 
noticing that there were others seated with her. The Health Care Aide tried to give Molly another spoonful of cereal but Molly pushed her hand away as she established eye contact with each of the others at the table to acknowledge their presence. Then reaching her wavering hand to the back of her neck, she struggled to pull something from underneath her bib. Extending her arm appeared to cause her pain and discomfort and yet she persisted. Molly eventually revealed a string of pearls she was wearing that had been covered by her bib. She allowed the pearls to pass through her long slender perfectly manicured fingers placing them ever so delicately atop her bib. With this simple gesture, Molly emerged from her world of decrepitude, incontinence, dementia and helplessness as a woman of grace and style. Now ready to eat her breakfast, Molly accepted the spoonful of cereal the Health Care Aide again tried to feed her. Pleased that Molly was now eating, the Health Care Aide continued to feed her without ever responding to Molly's proud display of her pearls.

Working with the series of five vignettes, Kontos initially drafted the scripts for the performance. However, recognizing that playwrights and artistic directors have a better eye and feel for the artistry of constructing performance pieces than ethnographers (Mienczakowski, 2001), Kontos created a partnership with ACT II Studio, a theatre school and creative drama centre for older adults, which is part of the Seniors Education Programs in Ryerson University's G. Raymond Chang School of Continuing Education, Toronto, Canada. ACT II Studio has a demonstrated history of developing socially relevant dramas for public presentation. Their director, Vrenia Ivonoffski, agreed to provide artistic directorship.

The collaborative process began with a meeting between Kontos, Ivonoffski, and a group of interested actors. All were provided with descriptions of the research participants who feature in the five vignettes. Five actors committed to the project, all having had some personal experience with Alzheimer's disease, which was agreed upon by Kontos and Ivonoffski as necessary background to sensitize them to the general 
condition of the illness and, as much as possible, to the nuances of embodiment in the lived experience of the illness. As Stucky (1993) writes, re-representational theatre involves performing a person as opposed to a persona or character, which requires an understanding of "bodiliness", what in phenomenological terms is referred to as our embodied way of "being-in-the-world" (Merleau-Ponty, 1962). In a performance about Alzheimer's disease, the body assumes even greater significance because it becomes the fundamental means by which persons who are cognitively impaired remain engaged with the world.

The process of working with the artistic director and actors continued in subsequent meetings where scripts were read aloud and the background material was discussed. With little dialogue in the scripts it was clear to the troupe that it would be the body and not the spoken word that reveals selfhood. Preparatory discussions thus revolved around the importance of the body as an active, communicative agent, imbued with its own wisdom, intentionality, and purposefulness. Despite the general consensus regarding the importance of the body in rendering visible expressions of personhood as depicted in each of the five vignettes, the challenge that faced the troupe was that the five vignettes, participant descriptions, and scripts did not provide much detail to help the actors achieve what Stucky has described as "kinetic understanding" (1993: 172). By contrast, in the case of interview research, tape-recordings preserve data from the lived event, providing a rich natural text that serves as a reference for actors. Through repeated listening, actors are able to study the complexity of natural speech including a range of paralinguistic detail (e.g. speaking tempo, vocal pitch, intonational contours) that gives 
them access to the original participants of the research in a way that written text alone cannot (Stucky, 1993).

The turning point in the process of developing the performance was when the troupe began to act through the scenes, engaging their bodies and not just their minds, to explore strategies for the re-enactment of embodied experiences from the original ethnographic research. The challenge of re-presentational theatre is to have a second body do much of what a prior body has already done (Stucky, 1993), and thus bodily participation was not only a mode of intensifying understanding of the nuances of embodiment in the lived experience of the illness as observed by Kontos, but also of portraying those experiences with the highest possible degree of verisimilitude and mimesis. Kontos thus played a key role in the production of the performance since she, being the ethnographer, had the most intimate connection to the actual actions, emotions and words of those who inhabited the original ethnographic setting that the actors were to re-present. Despite the significance of the original data gathering setting, Expressions of Personhood in Alzheimer's is nonetheless a theatrical event, and thus, as the actors began to explore their roles with their bodies, Ivonoffski's indispensable expertise was critically important in overseeing the project's status as aesthetic and theatrical communication. The scripts for example were revised to convey the meaning of the scene more succinctly, to connect more easily to an adjoining passage, to accommodate staging considerations, and to "condense 'real-time' for the purposes of dramatic economy" (Saldaña, 2003: 225).

As noted earlier, the development of Expressions of Personhood in Alzheimer's is part of a larger research agenda of ours to humanize the practice of dementia care. With 
the production now complete we are embarking upon the next stage of our research, which involves the performance of this drama at the outset of focus groups we are conducting with nurses and ancillary health care professionals in three different longterm care facilities. It is anticipated that responses to the performance by the focus group participants will serve as a springboard for discussion about embodied selfhood, how perceiving a broader range of behaviour as meaningful could enhance communication and the development of interpersonal relationships, and how this could ultimately improve the quality of caregiving and the quality of life of those living with Alzheimer's disease.

\section{Conclusion}

There is consensus in the knowledge translation literature that nurses and ancillary health personnel will embrace and integrate new knowledge into practice only if it is accessible and understandable (Closs \& Cheater, 1994), and if research findings are clearly presented and accompanied by a detailed discussion of their utility, relevance, and practicality in particular settings (Loomis, 1985; Mottola, 1996). There is also increasing recognition of the need for gerontological practice in general, and Alzheimer's care in particular, to be based on theory and basic research findings (Farkas et al., 2003; Pillemer et al., 2003). The utilization of research findings and the adoption of theory-based techniques by clinical practice are precisely the areas where the notion of embodied selfhood can make an important contribution. However, the translation of the notion of embodied selfhood into a framework that is meaningful to nurses, occupational therapists, physiotherapists, and recreational therapists is crucial in order for the notion to be successfully adopted in practice. 
As a method of communicating social knowledge, performance is powerful, evocative, complex, and dialogical. It privileges "the experience of knowledge" (Paget, 1993: 39, original emphasis), the communicative act of life as it is lived. In describing performance, Paget uses the term "concretion" (1993: 39) in contrast to abstraction of experience. She explains that concretions "display movement, process, change, and transformation" and that they are "expressive, sensitive, and experience-near" (1993: 40). As such they offer the potential to make empathic connections with audience members, and, as Gray et al. state (2000: 143), "it is exactly such empathy that is arguably the precondition for transformation of health care". When qualitative research is translated into drama, the emotional engagement of audiences is fostered by the audience's awareness that the staged re-presentations they are witnessing are based upon real lives. In the case of the production Expressions of Personhood in Alzheimer's, performed re-presentations are intended to connect and confront audiences with actual expressions of personhood in dementia. Other research-based dramatic performances have successfully revised audiences' perspectives on an issue by the sheer emotional impact of the performance (Gray et al., 2003; Mienczakowski, 1999). It is our contention that using the tools of dramatic discovery to foster awareness and deeper understanding of the ways in which persons with dementia remain connected to the world has the same potential to induce change. Ours is an agenda to create a new paradigm in dementia care that respects individuals with Alzheimer's disease as embodied beings deserving of dignity and worth. We believe that the performance paradigm and its aesthetic practices hold the promise of bringing about the transformational shift needed in order to achieve this. 


\section{Acknowledgments}

This study was generously funded by the Collaborative Research Program: Rehabilitation \& Long-Term Care, the Canadian Nurses Foundation, and the Nursing Care Partnership.

Dr. Kontos is supported by the Canadian Institutes of Health Research Fellowship Program, the Canadian Institutes of Health Research, Supporting Institutes (Knowledge Translation Branch, Institute of Health Services and Policy Research, and Institute of Gender and Health), and the Health Care, Technology \& Place Research Training Program. Dr. Naglie is supported by the Mary Trimmer Chair in Geriatric Medicine Research, University of Toronto. Toronto Rehabilitation is supported by a grant from the Ontario Ministry of Health and Long-Term Care. The views expressed here do not necessarily reflect those of our supporters or funders.

\section{NOTES}

\footnotetext{
${ }^{1}$ This study is based on Kontos' doctoral research (2003), Department of Public Health Sciences, University of Toronto.
} 


\section{References}

Bakhtin, M. M. (1986) Speech Genres and Other Late Essays. Austin: University of Texas Press.

Boal, A. (1992) Games for Actors and Non-Actors. New York: Routledge.

Bourdieu, P. (1977) Outline of a Theory of Practice (R. Nice, Trans.). Cambridge:

Cambridge University Press.

Bourdieu, P. (1990) The Logic of Practice (R. Nice, Trans.). Cambridge: Polity Press.

Clifford, J. (1986) 'Introduction: Partial Truths', in J. Clifford \& G. Marcus (eds) Writing Culture: The Poetics and Politics of Ethnography. Berkeley: University of California Press.

Clifford, J. (1988) Predicament of Culture. Cambridge: Harvard University Press.

Closs, C., \& Cheater, F. (1994) 'Utilization of Nursing Research: Culture, Interest, and Support', Journal of Advanced Nursing 19(4): 762-773.

Conquergood, D. (1991) 'Rethinking Ethnography: Towards a Critical Cultural Politics', Communication Monographs 58(June): 179-194.

Conquergood, D. (1992) 'Ethnography, Rhetoric, and Performance', Quarterly Journal of Speech 78: 80-123.

Csordas, T. (1994) 'Introduction: The Body as Representation and Being-in-theWorld', in T. Csordas (ed) Embodiment and Experience: The Existential Ground of Culture and Self, pp. 1-24. Cambridge: Cambridge University Press.

Dalziel, W. B. (1994) 'Dementia: No longer the Silent Epidemic', Canadian Medical Association Journal 151(10): 1407-1409. 
Davis, D. (2004) 'Dementia: Sociological and Philosophical Constructions', Social Science and Medicine 58: 369-378.

Denzin, N. (1997) Interpretive Ethnography: Ethnographic Practices for the 21st Century. Thousand Oaks: SAGE.

Denzin, N. (2000) 'Aesthetics and the Practices of Qualitative Inquiry', Qualitative Inquiry 6(2): 256-265.

Eisner, E. (1988) The Role of Discipline-Based Art Education in American Schools. Los Angeles: Paul Getty Trust.

Eisner, E. (1998) The Enlightened Eye: Qualitative Inquiry and the Enhancement of Educational Practice. Upper Saddle river, NJ: Merrill.

Ekman, S., Norberg, A., Viitanen, M., \& Winblad, B. (1991) 'Care of Demented Patients with Severe Communication Problems', Scandinavian Journal of Caring Sciences 5(3): 163-170.

Emerson, R., Fretz, R., \& Shaw, L. (2001) 'Participant Observation and Fieldnotes', in P. Atkinson \& A. Coffey \& S. Delamont \& J. Lofland \& L. Lofland (eds) Handbook of Ethnography, pp. 352-368. London: SAGE.

Fabian, J. (1990) Power and Performance: Ethnographic Explorations through Proverbial Wisdom and Theater in Shaba, Zaire. Wisconsin: University of Wisconsin Press.

Farkas, M., Jette, A., Tennstedt, S., Haley, S., \& Quinn, V. (2003) 'Knowledge Dissemination and Utilization in Gerontology: An Organizing Framework', The Gerontologist 43(Special Issue 1): 47-56. 
Fontana, A., \& Smith, R. W. (1989) 'Alzheimer's Disease Victims: The 'Unbecoming' of Self and the Normalization of Competence', Sociological Perspectives 32(1): 35-46.

Gray, R., Fitch, M., Labrecque, M., \& M., G. (2003) 'Reactions of Health Professionals to a Research-Based Theatre Production', Journal of Cancer Education 18(4): 223-229.

Gray, R., Ivonoffski, V., \& Sinding, C. (2002) 'Making a Mess and Spreading it Around: Articulation of an Approach to Research-Based Theatre', in A. Bochner \& C. Ellis (eds) Ethnographically Speaking, pp. 57-75. Walnut Creek, CA: Altamira Press.

Gray, R., Sinding, C., \& Fitch, M. (2001) 'Navigating the Social Context of Metastatic Breast Cancer: Reflections on a Project Linking Research to Drama', Health 5(2): $233-248$.

Gray, R., Sinding, C., Ivonoffski, V., Fitch, M., Hampson, A., \& Greenberg, M. (2000) 'The Use of Research-Based Theatre in a Project Related to Metastatic Breast Cancer', Health Expectations 3: 137-144.

Heritage, P. (1994) 'The Courage to be Happy: Augusto Boal, Legislative Theatre, and the 7th International Festival of the Theatre of the Oppressed', The Drama Review 38(3): $25-34$.

Jackson, M. (1996) 'Introduction: Phenomenology, Radical Empiricism, and Anthropological Critique', in M. Jackson (ed) Things as They Are: New Directions in Phenomenological Anthropology, pp. 1-50. Bloomington: Indiana University Press. 
Jonas-Simpson, C. (2001) 'From Silence to Voice: Knowledge, Values, and Beliefs Guiding Healthcare Practices with Persons Living with Dementia', Nursing Science Quarterly 14(4): 304-310.

Kitwood, T. (1997) Dementia Reconsidered: The Person Comes First. Buckingham: Open University Press.

Kontos, P. (2003). Embodied Selfhood: An Ethnography of Alzheimer's Disease. Unpublished doctoral dissertation, University of Toronto.

Kontos, P. (2004a) 'Embodied Selfhood: Redefining Agency in Alzheimer's Disease', in E. Tulle (ed) Old Age and Agency, pp. 105-121. New York: Nova Science Publishers.

Kontos, P. (2004b) 'Ethnographic Reflections on Selfhood, Embodiment and Alzheimer's Disease', Ageing and Society 24: 829-849.

Kontos, P. (2005) 'Embodied Selfhood in Alzheimer's Disease: Rethinking Person-Centred Care', Dementia: The International Journal of Social Research and Practice 4(4): 553-570.

Loomis, M. (1985) 'Knowledge Utilization and Research Utilization in Nursing', IMAGE: Journal of Nursing Scholarship 17(2): 35-39.

Luker, K. A., Austin, L., Caress, A., \& Hallett, C. E. (2000) 'The Importance of 'Knowing the Patient': Community Nurses' Constructions of Quality in Providing Palliative Care', Journal of Advanced Nursing 31(4): 775-782.

Merleau-Ponty, M. (1962) Phenomenology of Perception (C. Smith, Trans.). London: Routledge \& K. Paul. 
Mienczakowski, J. (1992) Syncing Out Loud: A Journey Into Illness. Brisbane, Australia: Griffith University Reprographics.

Mienczakowski, J. (1995) 'The Theater of Ethnography: The Reconstruction of Ethnography into Theater with Emancipatory Potential', Qualitative Inquiry 1(3): 360375.

Mienczakowski, J. (1999) 'Ethnography in the Hands of Participants: Tools of Dramatic Discovery', Studies in Educational Ethnography 2: 145-161.

Mienczakowski, J. (2001) 'Ethnodrama: Performed Research - Limitations and Potential', in P. Atkinson \& A. Coffey \& S. Delamont \& J. Lofland \& J. Lofland (eds) Handbook of Ethnography, pp. 468-476. London: SAGE.

Mienczakowski, J., \& Morgan, S. (1993) Busting: The Challenge of the Drought Spirit. Brisbane: Griffith University Reprographics.

Mienczakowski, J., Smith, L., \& Morgan, S. (2002) 'Seeing Words - Hearing Feelings: Ethnodrama and the Performance of Data', in C. Bagley \& M. Cancienne (eds) Dancing the Data, pp. 34-52. New York: Peter Lang.

Mottola, C. (1996) 'Research Utilization and the Continuing Staff Development Educator', Journal of Continuing Education in Nursing 27(4): 168-173.

Norberg, A., \& Asplund, K. (1990) 'Caregivers' Experience of Meaning in Caring for Severely Demented Patients in the Terminal Phase of Life', Western Journal of Nursing Research 12(1): 75-84.

Paget, M. (1993) A Complex Sorrow: Reflections on Cancer and an Abbreviated Life. Philadelphia: Temple University Press. 
Phelan, P. (1997) Mourning Sex: Performing Public Memories. London:

Routledge.

Pillemer, K., Suitor, J., \& Wethington, E. (2003) 'Integrating Theory, Basic

Research, and Intervention: Two Case Studies from Caregiving Research', The

Gerontologist 43(Special Issue 1): 19.

Saldaña, J. (2003) 'Dramatizing Data: A Primer', Qualitative Inquiry 9(2): 218236.

Sinding, C., Gray, R., Fitch, M., \& Greenberg, M. (2002) 'Staging Breast Cancer, Rehearsing Metastatic Disease', Qualitative Health Research 12(1): 61-73.

Stucky, N. (1993) 'Toward an Aesthetics of Natural Performance', Text and Performance Quarterly 13: 168-180.

Tappen, R. M., Williams, C., Fishman, S., \& Touhy, T. (1999) 'Persistence of Self in Advanced Alzheimer's Disease', Image: Journal of Nursing Scholarship 31(2): 121125.

Turner, V. (1986) The Anthropology of Performance. New York: Performing Arts Journal Publications.

Tyler, S. (1987) The Unspeakable: Discourse, Dialogue and Rhetoric in the Postmodern World. Madison: University of Wisconsin Press.

Whittemore, R. (2000) 'Consequences of Not "Knowing the Patient"', Clinical Nurse Specialist 14(2): 75-81. 
Dr. Kontos obtained her PhD from the University of Toronto, Department of Public Health Sciences. She is presently a Postdoctoral Fellow at Toronto Rehabilitation Institute, a teaching hospital of the University of Toronto. Her research interests are embodiment, personhood, Alzheimer's disease, and ethnodrama. She has published articles in Ageing and Society, Journal of Aging Studies, Dementia: The International Journal of Social Research and Practice, Health and Place, Sociology of Health and Illness, and Philosophy in the Contemporary World. She has also contributed to several edited volumes including Old Age and Agency, Ageing and Place: Perspectives, Policy and Practice, and Thinking About Dementia: Culture, Loss and the Anthropology of Senility.

Address: Toronto Rehabilitation Institute, 1002-550 University Avenue, Toronto, Ontario, M5G 2A2, Canada [email: kontos.pia@ torontorehab.on.ca]

Dr. Naglie is a geriatrician and senior scientist at Toronto Rehabilitation Institute and University Health Network (Toronto General Research Institute). He holds the Mary Trimmer Chair in Geriatric Medicine Research, University of Toronto. His research focuses on outcomes evaluation in frail older persons. He has published articles in a variety of medical and methodological journals and has recently authored a chapter in the 2nd edition of the Oxford Textbook of Geriatric Medicine. He is currently the principal investigator of a Canadian study on the quality of life in Alzheimer's disease. Address: Toronto Rehabilitation Institute, 1008-550 University Avenue, Toronto, Ontario, M5G 2A2, Canada [email: naglie.gary@torontorehab.on.ca] 